MATEC Web of Conferences 13, 02025 (2014)

DOI: $10.1051 /$ matecconf/ 20141302025

(C) Owned by the authors, published by EDP Sciences, 2014

\title{
Performance and Emission Assessment of Multi Cylinder Diesel Engine using Surfactant Enhanced Water in Diesel Emulsion
}

\author{
Mohammed Yahaya Khan ${ }^{1, a}$, Z.A.Abdul Karim ${ }^{1}$, A. Rashid A. Aziz ${ }^{1}$ and Isa M Tan ${ }^{2}$ \\ ${ }^{1}$ Department of Mechanical Engineering, Universiti Teknologi Petronas, Malaysia \\ ${ }^{2}$ Department of Fundamental \& Applied Science, University Teknologi Petronas, Malaysia
}

\begin{abstract}
A four stroke, four cylinder, In-direct injection diesel engine was used to study the effect of emulsified diesel fuel with $5 \%$ water by volume on the engine performance and on the main pollutant emissions. The experiments were conducted in the speed range from 1000 to $4500 \mathrm{rpm}$ at full load conditions. It was found that, in general, using emulsified fuel improves the engine performance with slight increase in emissions. While the BSFC has a minimum value for $5 \%$ water and at all $\mathrm{rpm}$, the torque, the power and the BMEP are found to have maximum values under these conditions when compared conve ntional disel. $\mathrm{CO}_{2}$ was found to increase with engine speed whereas increase in $\mathrm{CO}$ and NOX were minimum. In this work water in diesel emulsion was prepared by a mechanical homogenizer and their physical and chemical properties were examined.
\end{abstract}

Keywords: Diesel engine; Water in Diesel Emulsion (WiDE); Pollutant emissions; Surfactant

1. Introduction Diesel engines offer better fuel to power conversion efficiency and due to their better fuel economy, diesel engines are the dominant class of engines in mass transportation, heavy industries and agricultural sectors. In spite of their preferable advantages, they are one of the major pollution contributors to the environment. Primary pollutants emitted from diesel engines are particulate matters (PM), black smoke, nitrogen oxides (NOx), sulfur oxides (SOX), unburned hydrocarbon $(\mathrm{HC})$, carbon monoxide $(\mathrm{CO})$, and carbon dioxide $\left(\mathrm{CO}_{2}\right)$ [1]. Increasing stringent regulation on exhaust emissions drives a major research endeavor in engine development in order to reduce these pollutants. Significant reduction targets include reduction of PM from $0.025 \mathrm{~g} / \mathrm{km}$ in Euro 4 (2005) to $0.0045 \mathrm{~g} / \mathrm{km}$ in Euro 6 (2014) for both CI passenger cars and light commercial vehicles, which account for a $82 \%$ reduction. Similar reduction targets are also imposed on heavyduty engines with a reduction of 50\% in PM emission [2].

Researches showed that water-in-diesel emulsions used as a fuel in CI engines can lead to reductions in the adiabatic flame temperature resulting in measurable reductions in the $\mathrm{NO}_{\mathrm{X}}$ emissions [3, 4]. As for PM emissions, the presence of water during the intensive formation of soot particles seems to reduce the rate of formation of soot particles and enhance their burnout by increased concentration of oxidation species such as $\mathrm{OH}[5]$.

2. Experimental Set up and Tests Two phase stable WiDE with $5 \%$ water was prepared using mechanical homogenizer. In house developed surfactant, pure diesel, and distilled water was used for emulsion preparation.Homogenized WiDE was tested on Ford-XLD 4 cylinder

\footnotetext{
${ }^{a}$ Corresponding author : mohammedyahayakhan@yahoo.com
}

This is an Open Access article distributed under the terms of the Creative Commons Attribution License 2.0, which permits unrestricted use, distribution, and reproduction in any medium, provided the original work is properly cited. 
indirect injection diesel engine for the speed range of $1000 \mathrm{rpm}$ to $4500 \mathrm{rpm}$ at full load conditions.

Figure 1.shows the schematic illustration of experimental setup.

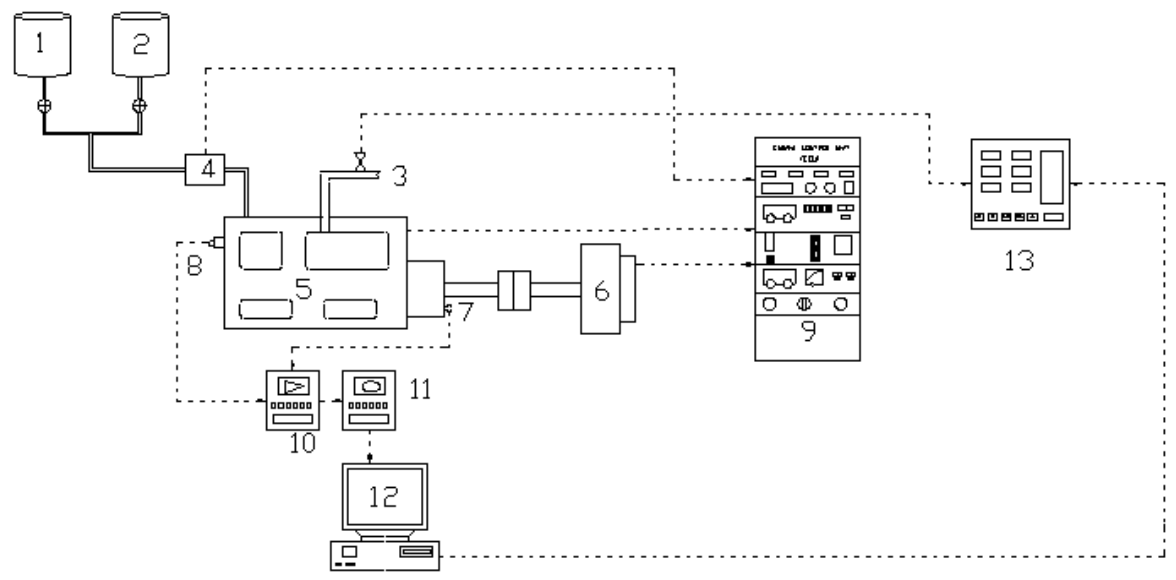

Figure 1 Schematic illustration of experimental setup.

1.Diesel Tank, 2.Emulsion Tank, 3.Exhaust, 4.Fuel flow meter, 5.Engine, 6.Eddy Current Dynamometer, 7.Angle Encoder,8. Pressure Transducer, 9.Engine Control Unit, 10.Signal Amplifier, 11.Data Acquisition System, 12.Computer, 13.Gas Analyser.

The SVM 3000 Viscometer was used to measure the dynamic viscosity and density of WiDE and Diesel according to ASTM D7042 at different temperatures. Calorific values of the fuels were obtained using Leco AC-350 bomb calorimeter which was calibrated using standard benzoic acid as standard. Chemical characteristics were analysed using CHNS analyser. Exhaust emissions were measured by MRU Vario plus Industrial exhaust gas analyser.

\section{Results and Discussions}

\subsection{Laboratory Testing}

3.1.1 Density and Viscosity Viscosity for both WiDE and conventional diesel were measured at $20^{\circ} \mathrm{C}$ to $100^{\circ} \mathrm{C}$. With $5 \%$ of water content viscosity of WiDE was observed to be on the higher side compared to pure diesel at all measured temperatures as shown in Figure 2.As expected that higher viscosity of WiDE with increasing water content, also it is claimed that the Presence of water will affect the ignition delay [6].

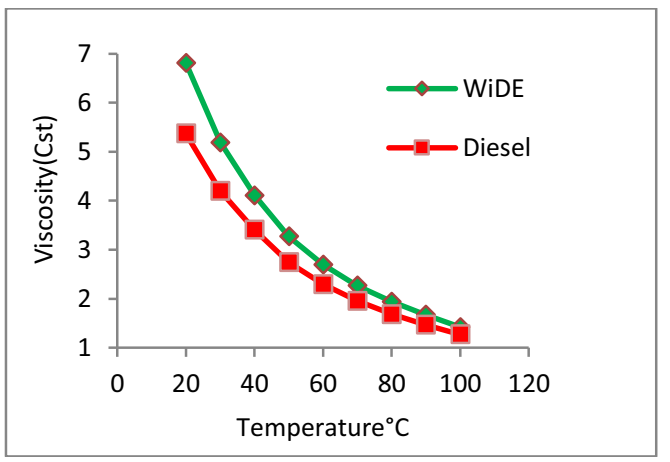

Figure 2. Viscosity of WiDE \& Diesel

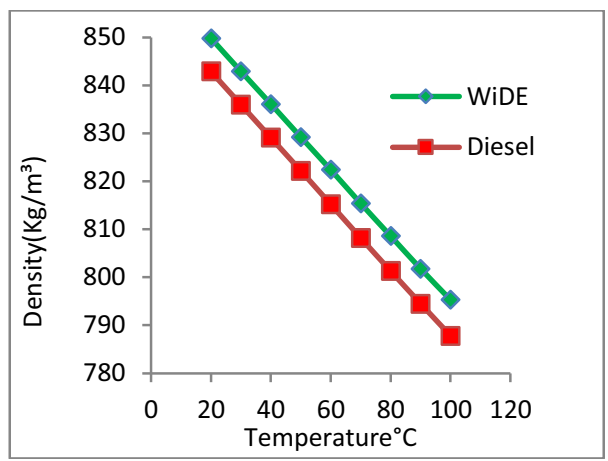

Figure 3. Density of WiDE \& Diesel 
Figure 3. depicts the density for both WiDE and pure diesel was measured at different temperatures. It is observed that when compared to pure diesel, WiDE has higher value of $7 \mathrm{~kg} / \mathrm{m}^{3}$ and is maintained irrespective of all temperatures starting from $20^{\circ} \mathrm{C}$ to $100^{\circ} \mathrm{C}$. Increase in density is attributed to the higher density of water that is being added to diesel fuel which is of lower density.

3.1.2 Calorific Value and CHNS Analysis It is obvious presence of water leads to lower heating value of WiDE and can be attributed to slight reduction in engine power when used as fuel [7]. As for as CHNS analysis is concerned, Nitrogen and Sulfur are less for WiDE, but carbon and hydrogen are on the higher side when compared to pure diesel as mentioned in Table 1.

Table-1 Calorific value and CHNS values of Diesel and WiDE

\begin{tabular}{|c|c|c|}
\hline \multirow{2}{*}{ Properties } & \multicolumn{2}{|c|}{ Sample } \\
\cline { 2 - 3 } & Diesel & WiDE \\
\hline Calorific value $[\mathrm{J} / \mathrm{g}]$ & 46252 & 44250 \\
\hline $\mathrm{C}[\% \mathrm{w} / \mathrm{w}]$ & 81.38 & 82.57 \\
\hline $\mathrm{H}[\% \mathrm{w} / \mathrm{w}]$ & 11.86 & 11.97 \\
\hline $\mathrm{N}[\% \mathrm{w} / \mathrm{w}]$ & 0.1013 & 0.1357 \\
\hline $\mathrm{S}[\% \mathrm{w} / \mathrm{w}]$ & 0.126 & 0.12 \\
\hline
\end{tabular}

\subsection{Performance Characteristics of Engine}

3.2.1 Engine Torque The effect of water addition in the form of emulsions on the engine output for various speeds is shown in Figure 4. Similar trend was also reported by Abu Zaid [8] as a function of engine's speed. At low speed torque increases as the engine speed increases, reaches maximum and then decreases with increase in engine speed because at higher speeds engine is unable to ingest full charge of air. Torque developed by the test engine was found to be higher in case of WiDE at all speeds as shown. Maximum torque produced by WiDE was $85 \mathrm{Nm}$ at $3000 \mathrm{rpm}$, whereas it was $81 \mathrm{Nm}$ with diesel at 2000rpm.

3.2.2. Engine Power The power produced by the emulsion was found to be the closest power output to that of neat diesel at speeds ranging from 1000 to $2000 \mathrm{rpm}$ then, it is evident from Figure 5 . that power produced by the WiDE with $5 \%$ water is increasing after $2000 \mathrm{rpm}$ and reaches maximum of $34.4 \mathrm{~kW}$.

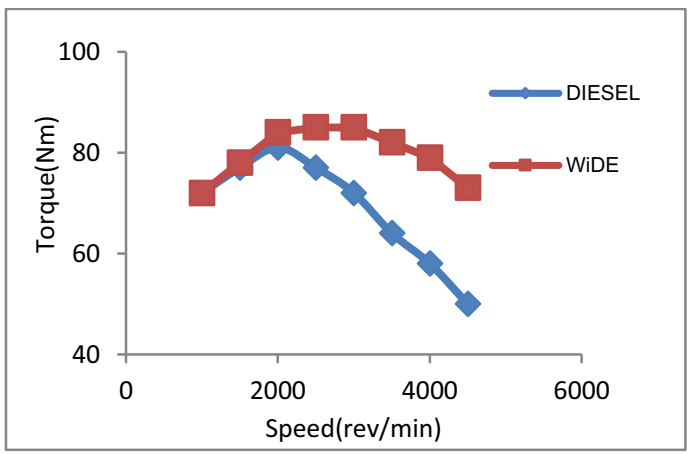

Figure 4. Engine torque for diesel and WiDE

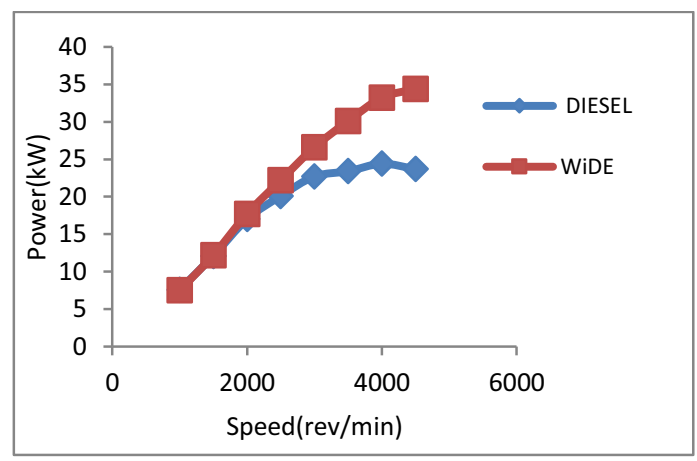

Figure 5. Engine power for diesel and WiDE 
3.2.3 Specific Fuel Consumption SFC at lower engine speeds between 1000rpm and 2000rpm there is no significance change between diesel and WiDE, but as the speed increases SFC for WiDE is comparatively lower than diesel, which is in agreement with results of Abu Zaid [8]. Figure 6. shows the SFC for both diesel and WiDE.

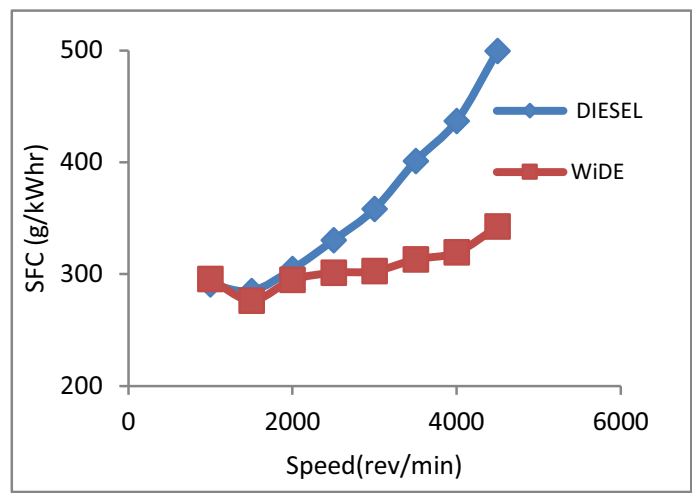

Figure 6. SFC for diesel and WiDE

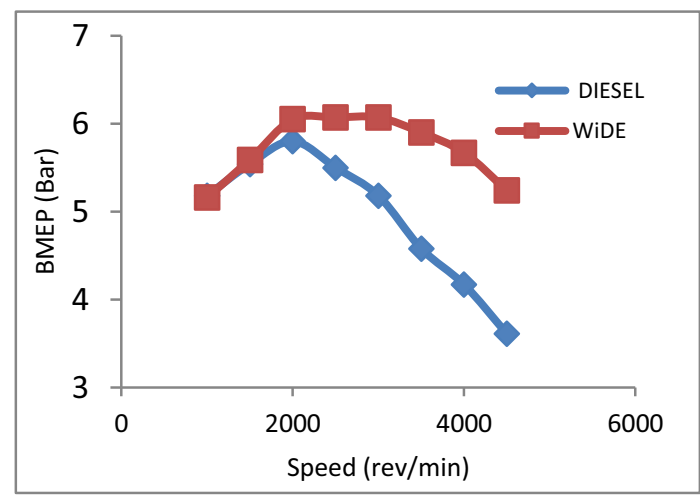

Figure 7. BMEP for diesel and WiDE

3.2.4 Engine's BMEP Significant increase in BMEP is observed with WiDE after 2000rpm than diesel as shown in Figure 7. At highest speed the difference was found to be maximum of $31 \%$ more than diesel. At lowers rpms the difference in BMEP was insignificant.

3.2.5 Emission Characteristics of Engine CO level for WiDE was lesser than diesel at lowest speed of $1000 \mathrm{rpm}$ and started increasing to a maximum at 2000rpm as shown in Figure 8.Then a declining trend was observed between 3500 and $4500 \mathrm{rpm}$, rise in temperature can be attributed to the reduction in $\mathrm{CO}$ at higher speeds [9] . Same trend was followed by both diesel and WiDE in terms of NOx emission Figure 9. For WiDE at lower speeds and higher speeds NOx was slightly higher than diesel but at intermediate speed of 2500rpm and 3000rpm it merges with diesel. In general, the level of Nox was higher than the diesel which is not in accordance with other research findings $[9,10] . \mathrm{CO}_{2}$ for WiDE was found to be higher than diesel at all speeds as shown in Figure 9.At minimum and maximum speed $\mathrm{CO}_{2}$ was about $9.6 \%$ higher than diesel, where as at $2000 \mathrm{rpm}$ hike was $24.6 \%$ as shown in Figure 10.

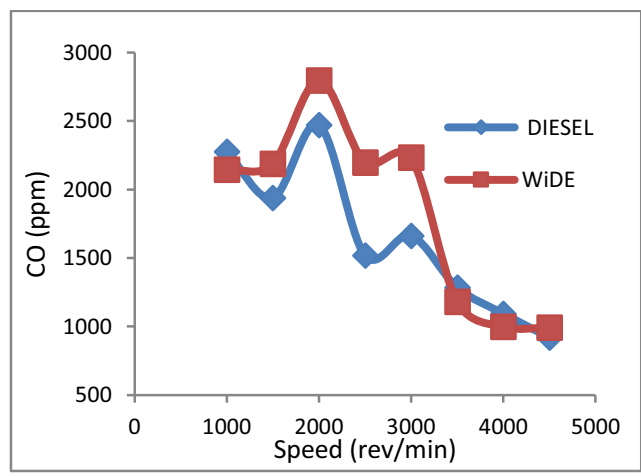

Figure 8. CO emissions for diesel and WiDE

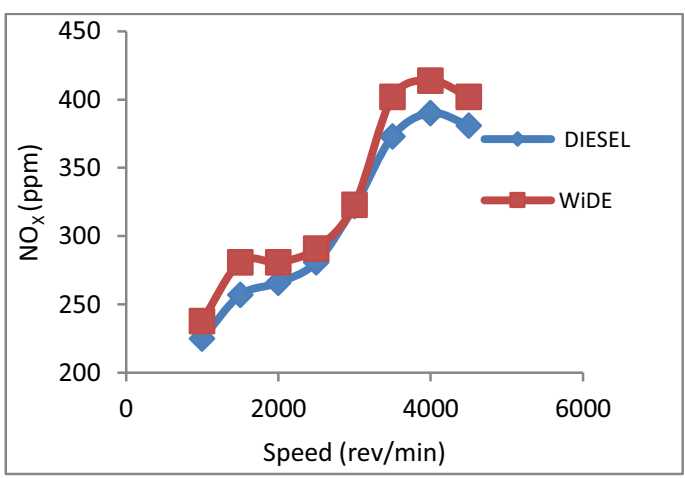

Figure 9 NOx emissions for diesel and WiDE 


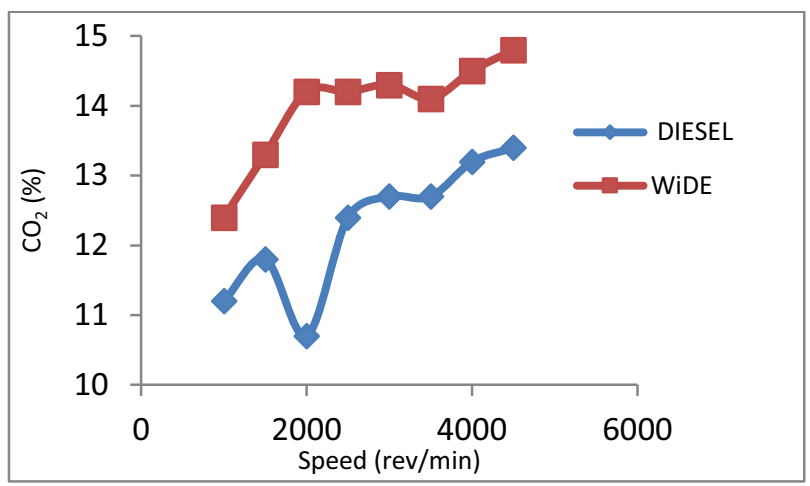

Figure 10. $\mathrm{CO}_{2}$ emissions for diesel and WiDE

Conclusion Water in Diesel emulsion with $5 \%$ water stabilized by in house developed surfactant was tested on multi cylinder diesel engine and performance was found better than diesel on the other hand certain emissions were found to be slightly increased which is contradictory to many researchers finding. To draw a conclusion about the effect of water content and influence of surfactant in the emulsion properties and on engine behavior it is recommended to carry out the performance, emission and combustion analysis tests for various percentages of water and stabilized by different surfactants.

Acknowledgement The authors thank financial and facility support of Universiti Teknologi PETRONAS. SIT Schiffs \& Industrie Technik (M) Sdn Bhd is highly acknowledged for preparing WiDE.

\section{References}

[1] C.Y Lin, K.H Wang, Fuel 82, 1367-1375 (2003)

[2] Information on Directives and regulations motor vehicles: http://ec.europa.eu

[3] O. Armas, R. Ballesteros, F.J. Martos, J.R. Agudelo, Fuel 84, 1011-1018 (2005)

[4] J. Ghojel, D. Honnery, K. Al-Khaleefi, Appl Ther Eng 26 2132-2141 (2006)

[5] X.T. Tran, J. Ghojel, 5th Asia pacific Conference on Combustion,(2005)

[6] I. Jeong, K.H Lee, and J. Kim, J of Mech Sci and Tech 22 148-156 (2008)

[7] F.L Dryer, 16th symposium international on combustion, 321-36(1976)

[8] M. Abu-Zaid, Energy Conversion and Management 45, 697-705 (2004)

[9] E. A. Fahd ,Y. Wenming, P.S. Lee, S.K. Chou ,C.R. Yap, Appl. Energy 102, 1042-1049 (2013)

[10] Subramanian, Energy Conversion and Management 52, 849-857 (2011) 